\title{
Pengaruh Jumlah Industri dan Tenaga Kerja Terhadap Nilai Produksi Industri Formal Kecil
}

\author{
Mu’tasim Billah ${ }^{1}$, Mohammad Syaiful Pradana ${ }^{2}$ \\ ${ }^{1}$ Universitas Islam Darul Ulum Lamongan, mutasimaim@gmail.com \\ ${ }^{2}$ Universitas Islam Darul Ulum Lamongan, syaifulp@unisda.ac.id
}

\begin{abstract}
The purpose of this study to analyze the effect of the number of industries and labor on the value of production in small industries in Lamongan Regency using the Durbin-Watson test. The Durbin-Watson test is an autocorrelation test that assesses the presence of autocorrelation in residuals. Data taken from the Central Bureau of Statistics of Lamongan Regency. Furthermore, it was analyzed using SPSS assistance. Based on the results of the analysis, it is known that there is no autocorrelation between the number of industries and workers on the value of production in small industries in Lamongan Regency.
\end{abstract}

Keywords: Autocorrelation, Durbin-Watson, Lamongan,

\begin{abstract}
Abstrak. Penelitian ini bertujuan untuk menganalisis pengaruh jumlah industri dan tenaga kerja terhadap nilai produksi pada industri kecil di Kabupaten Lamongan menggunakan uji Durbin-Watson. Uji Durbin-Watson adalah uji autokorelasi yang menilai adanya autokorelasi pada residual. Data diambil dari Badan Pusat Statistik Kabupaten Lamongan. Selanjutnya, dianalisis dengan menggunakan bantuan SPSS. Berdasarkan hasil analisis diketahui tidak terdapat autokorelasi antara jumlah industri dan tenaga kerja terhadap nilai produksi pada industri kecil di Kabupaten Lamongan.
\end{abstract}

Kata Kunci: Autokorelasi, Durbin-Watson, Lamongan

\section{Pendahuluan}

Salah satu permasalahan pokok dalam pembangunan ekonomi yang di hadapi oleh setiap negara sedang berkembang adalah masalah pembangunan ekonomi dan penduduk, dimana terbatasnya kesempatan kerja dan rendahnya tingkat pendapatan masyarakat. Indonesia sebagai salah satu negara sedang berkembang tidak terlepas dari masalah tersebut. Pertambahan penduduk semakin bertambah, tentu akan menimbulkan permasalahan yang semakin kompleks, karena penambahan jumlah penduduk tidak diikuti pertumbuhan ekonomi. Sehingga lapangan kerja yang tersedia tidak mampu menampung jumlah tenaga kerja yang tersedia. Kabupaten Lamongan sebagai salah satu kabupaten di Indonesia tidak terlepas dari permasalahan-permasalahan tersebut. Untuk mengatasinya pemerintah telah berupaya menempuh berbagai kebijakan di berbagai bidang seperti kebijakan fiskal, moneter kebijakan dibidang pertanian, industri dan tenaga kerja. 
Salah satu sektor ekonomi yang mendapatkan prioritas utama dalam pembangunan adalah sektor industri. Sektor industri terus di tingkatkan dalam rangka meningkatkan kesejahteraan masyarakat. Pembangunan industri dipandang sebagai bagian dari pembangunan ekonomi untuk meningkatkan taraf hidup masyarakat. Dalam proses ini sektor industri diharapkan akan berkembang dan lebih kuat serta berdaya saing tinggi sehingga memungkinkan sektor industri memberikan sumbangan yang jauh lebih besar dari pada penerimaan devisa.

Pembangunan sektor industri mampu memberikan peran yang strategis dalam perekonomian nasional. Sumbangan dalam berbagai sektor pembangunan nasional adalah wujud nyata dan tidak perlu disangsikan, seperti menyerap tenaga kerja, memperluas lapangan kerja dan kontribusi terhadap penerimaan devisa negara. Sektor industri juga mampu berperan dalam meningkatkan pertumbuhan ekonomi secara bertahap dan seimbang sebagai upaya mewujudkan dasar yang lebih kuat dan lebih luas bagi pertumbuhan ekonomi pada umumnya, serta memberikan nilai tambah bagi pertumbuhan sektor industri khususnya. Dari sisi lain upaya pengembangan Industri Kecil tidak terlepas dari usaha pemerintah dalam mengentaskan kemiskinan. Oleh karena itu upaya pengembangan sektor ini menjadi tanggung jawab pemerintah dan semua lapisan masyarakat.

Salah satu upaya yang dilakukan untuk meningkatkan kinerja Industri Kecil disamping pembinaan adalah dengan menciptakan hubungan kemitraan dengan pengusaha kuat. Dengan adanya mitra kerja yang sudah besar dan kuat akan membantu pengusaha lemah untuk lebih berkembang dan bisa meningkatkan kualitas dan kuantitas Industri Kecil tersebut.

Pemerintah telah melakukan beberapa upaya untuk memacu pertumbuhan Industri Kecil di Indonesia diantaranya yaitu seperti yang ditegaskan dalam Pasal 3 Surat Keputusan Menteri Keuangan Republik Indonesia nomor 316/KMK.016/1994 [1], yaitu melakukan kemitraan dengan usaha berskala besar seperti BUMN agar adanya suasana saling mendukung dan berbagi informasi. Pemerintah juga mengadakan Gerakan Kemitraan Usaha Nasional (GKUN) yaitu dengan mewajibkan Badan Usaha Milik Negara untuk menyisihkan 1\% sampai dengan 3\% dari keuntungan sesudah dipotong pajak untuk dialokasikan ke dana pembinaan Industri Kecil berupa pinjaman lunak, di karenakan dana tersebut mempunyai bunga relatif rendah yaitu $2 \%$ sampai $6 \%$.

Bagi pengembangan Industri Kecil masalah modal merupakan kendala terbesar. Pada umumnya pembiayaan yang berasal dari kredit perbankan dirasakan oleh Industri Kecil memberatkan, terutama karena tingkat bunga yang cukup tinggi. Di lain pihak mengingat sektor Industri Kecil memiliki skala usaha yang kecil dengan tingkat pendapatan yang rendah dan tidak teratur, pihak perbankan sering merasa khawatir apabila pinjamannya tidak bisa di kembalikan oleh Industri Kecil.

Perkembangan nilai produksi industri kecil di Kabupaten Lamongan sampai saat ini terus mengalami perkembangan yang relatif cukup signifikan, bagi masyarakat Kabupaten Lamongan sektor industri kecil memegang peran penting dalam membangun perekonomian keluarga. Jenis industri kecil di Kabupaten Lamonganmulai dari industri makanan, minuman, tekstil, pakaian sampai dengan industri percetakan dan lain-lain, telah mengalmi kemajuan yang cukup berarti, karena industri kecil ini mampu menopang perekonomian rumah tangga. 
Dari sekian banyak industri kecil yang ada di Kabupaten Lamongan dapat dipahami bahwa sektor industri kecil ini memegang peranan penting bagi pembangunan dan kesejahteraan masyarakat, karena sektor ini dapat menyerap tenaga kerja, dan dapat mengurangi angka pengangguran. Penelitian ini bertujuan untuk menganalisis pengaruh jumlah industri dan tenaga kerja terhadap nilai produksi pada industri kecil di Kabupaten Lamongan menggunakan uji Durbin Watson.

\section{Tinjauan Pustaka}

Tenaga kerja dipilah ke dalam dua kelompok yaitu angkatan kerja dan bukan angkatan kerja. Angkatan kerja adalah tenaga kerja yang bekerja atau punya pekerjaan sementara, tidak bekerja dan sedang mencari pekerjaan. Sedangkan yang termasuk bukan angkatan tenaga kerja yang tidak mempunyai pekerjaan dan sedang tidak mencari pekerjaan, yakni orang-orang kegiatannya bersekolah (pelajar dan mahasiswa), mengurus rumah tangga (ibu-ibu yang bukan wanita karir), serta menerima pendapatan tetapi bukan imbalan langsung atas jasa kerjanya (pensiun).

Angkatan kerja yang tumbuh sangat cepat tentu saja akan membawa beban tersendiri bagi perekonomian, yakni penciptaan atau perluasan lapangan kerja. Jika lowongan kerja baru tidak mampu menampung semua angkatan kerja baru (dengan kata lain: tambahan permintaan akan tenaga kerja lebih sedikit dari pada tambahan penawaran angkatan kerja), maka sebagian angkatan kerja baru itu akan memperpanjang barisan penganggur yang sudah ada. Penciptaan lapangan kerja inilah yang sekarang menjadi salah satu masalah rawan dalam pembangunan ekonomi di Indonesia. Kerawananan yang ada, bukan semata-mata masalah jumlah; yakni bagaimana memacu jumlah yang diminta agar mampu menyerap jumlah yang ditawarkan, akan tetapi juga masalah mutu. Kualitas tenaga kerja Indonesia, sebagaimana tercermin dari tingkat pendidikan angkatan kerja dan produktivitas pekerja yang ada, masih relatif rendah.

\section{Metode Penelitian}

Penelitian ini akan menganalisis data dengan menggunakan uji autokorelasi Durbin-Watson dengan menggunakan software SPSS. Data yang digunakan dalam uji autokorelasi Durbin-Watson ini diperoleh dari Badan Pusat Statistik (BPS) Lamongan. Adapun variabel yang digunakan dalam penelitian ini yaitu: jumlah industry kecil, jumlah tenaga kerja dan nilai produksi.

Uji Autokorelasi merupakan salah satu uji asumsi klasik dalam analisis regresi linear berganda. Uji autokorelasi adalah untuk melihat apakah terjadi korelasi antara suatu periode t dengan periode sebelumnya (t-1). Secara sederhana adalah bahwa analisis regresi adalah untuk melihat pengaruh antara variabel bebas terhadap variabel terikat, jadi tidak boleh ada korelasi antara observasi dengan data observasi sebelumnya. Sebagai contoh adalah pengaruh antara tingkat inflasi bulanan terhadap nilai tukar rupiah terhadap dollar. Data tingkat inflasi pada bulan tertentu, katakanlah bulan Februari, akan dipengaruhi oleh tingkat inflasi bulan Januari. Berarti terdapat gangguan autokorelasi pada model tersebut. Contoh lainnya pengeluaran rutin dalam suatu rumah tangga. Ketika pada bulan Januari 
suatu keluarga mengeluarkan belanja bulanan yang relatif tinggi, maka tanpa ada pengaruh dari apapun, pengeluaran pada bulan Februari akan rendah.

Uji autokorelasi hanya dilakukan pada data time series (runtut waktu) dan tidak perlu dilakukan pada data pada kuesioner di mana pengukuran semua variabel dilakukan secara serempak pada saat yang bersamaan. Model regresi pada penelitian di Bursa Efek Indonesia di mana periodenya lebih dari satu tahun biasanya memerlukan uji autokorelasi.

Beberapa uji statistik yang sering dipergunakan adalah uji Durbin-Watson atau uji dengan run test dan jika data observasi di atas 100 data sebaiknya menggunakan uji Lagrange Multiplier. Beberapa cara untuk menanggulangi masalah autokorelasi adalah dengan mentransformasikan data atau bisa juga dengan mengubah model regresi ke dalam bentuk persamaan beda umum (generalized difference equation). Selain itu juga dapat dilakukan dengan memasukkan variabel lag dari variabel terikatnya menjadi salah satu variabel bebas, sehingga data observasi menjadi berkurang 1 .

Uji Durbin Watson adalah uji autokorelasi yang menilai adanya autokorelasi pada residual. Uji ini dilakukan dengan asumsi atau syarat antara lain: 1). model regresi harus menyertakan konstanta, 2). autokorelasi harus diasumsikan sebagai autokorelasi first order, dan 3). variabel dependen bukan merupakan variabel Lag.

Autokorelasi first order adalah korelasi antara sampel ke-i dengan sampel ke-i-1 seperti yang sudah dibahas di atas sebelumnya. Pada beberapa paket software statistika, output untuk uji asumsi autokorelasi pada error dengan Durbin-Watson statistics tidak menyertakan p-value sebagai alat pengambilan keputusan, sehingga pengguna masih harus menggunakan tabel Durbin-Watson bounds sebagai pembanding yaitu Durbin Upper (DU) dan Durbin Lower DL). Dikatakan tidak terdapat autokorelasi jika nilai $D W>D U$ dan $(4-D W)>D U$ atau bisa dinotasikan juga sebagai berikut: $(4-D W)>D U<D W[2]$.

\section{Hasil dan Pembahasan}

\subsection{Uji Deskriptif Data}

Pada tahap ini, yang harus dilakukan yaitu membuat dekripsi data dari jumlah industri kecil, jumlah tenaga kerja, dan nilai produksi industri kecil di kabupaten Lamongan. Langkah ini dilakukan untuk menunjukkan deskriptif data yang dianalisis. Hasil deskriptif data jumlah industri di kabupaten Lamongan dapat dilihat pada Tabel 1 berikut.

Tabel 1. Deskriptif Statistik Data

\begin{tabular}{lrrr}
\hline & $\begin{array}{c}\text { Jumlah Industri } \\
\text { kecil }\end{array}$ & $\begin{array}{c}\text { Jumlah Tenaga } \\
\text { Kerja }\end{array}$ & Nilai Produksi \\
\hline N (statistic) & 7 & 7 & 7 \\
Range (statistic) & 202 & 1058 & $1 . \mathrm{E} 7$ \\
Minimum (statistic) & 353 & 4945 & $4 . \mathrm{E} 8$ \\
Maximum (statistic) & 555 & 6003 & $4 . \mathrm{E} 8$ \\
Mean (statistic) & 436.57 & 5531.71 & $3.93 \mathrm{E} 8$ \\
Std. Deviation (statistic) & 71.600 & 411.554 & 5461823.457 \\
Variance (statistic) & $5.127 \mathrm{E} 3$ & $1.694 \mathrm{E} 5$ & $2.983 \mathrm{E} 13$ \\
Skewness (statistic) & .668 & -.195 & -.150
\end{tabular}




\begin{tabular}{lrrr} 
Skewness (Std. Error) & .794 & .794 & .794 \\
Kurtosis (statistic) & -.447 & -1.444 & -.969 \\
Kurtosis (Std. Error) & 1.587 & 1.587 & 1.587 \\
\hline
\end{tabular}

Berdasarkan output SPSS pada Tabel 1 diketahui bahwa jumlah data atau $N=7$, jumlah industri kecil minimum yaitu 353 , dan maximum 555 , rata-rata nilainya $=436,57$ dengan standar deviasi sebesar 71,6 . Nilai range merupakan selisih nilai minimum dan maksimum yaitu sebesar 202. Kurtosis dan skewness merupakan ukuran untuk melihat apakah data ini di distribusikan secara normal atau tidak. Skewness mengukur kemencengan dari data sedangkan Kurtosis mengukur puncak dari sitribusi data. Dasar pengambilan keputusannya yakni data berdistribusi normal jika nilai Skewness dan Kurtosis mendekati nol. Berdasarkan Tabel 1 diketahui bahwa nilai Skewness dan Kurtosis masing-masing 0,668 dan $-0,447$. Artinya dapat disimpulkan bahwa data Jumlah Industri Kecil terdistribusi normal.

Berdasarkan output SPSS pada Tabel 1 diketahui bahwa jumlah data atau $N=7$, jumlah tenaga kerja minimum yaitu 4945 , dan maximum 6003 , rata-rata nilainya $=5531,71$ dengan standar deviasi sebesar 411,554 . Nilai range merupakan selisih nilai minimum dan maksimum yaitu sebesar 1058 . Kurtosis dan skewness merupakan ukuran untuk melihat apakah data ini di distribusikan secara normal atau tudak. Skewness mengukur kemencengan dari data sedangkan Kurtosis mengukur puncak dari sitribusi data. Dasar pengambilan keputusannya yakni data berdistribusi normal jika nilai Skewness dan Kurtosis mendekati nol. Berdasarkan output di atas diketahui bahwa nilai Skewness dan Kurtosis masingmasing $-0,195$ dan $-1,444$. artinya dapat disimpulkan bahwa data Jumlah Industri Kecil terdistribusi normal.

Berdasarkan output SPSS pada Tabel 1 diketahui bahwa jumlah data atau $N=7$, jumlah tenaga kerja minimum yaitu 384997818 , dan maximum 399572818 , rata-rata nilainya $=393088960,857$ dengan standar deviasi sebesar 5461823,457 . Nilai range merupakan selisih nilai minimum dan maksimum yaitu sebesar 14575000 . Kurtosis dan skewness merupakan ukuran untuk melihat apakah data ini di distribusikan secara normal atau tudak. Skewness mengukur kemencengan dari data sedangkan Kurtosis mengukur puncak dari sitribusi data. Dasar pengambilan keputusannya yakni data berdistribusi normal jika nilai Skewness dan Kurtosis mendekati nol. Berdasarkan output di atas diketahui bahwa nilai Skewness dan Kurtosis masing-masing $-0,150$ dan $-0,969$. artinya dapat disimpulkan bahwa data Jumlah Industri Kecil terdistribusi normal.

\subsection{Uji Durbin Watson}

Model regresi yang baik adalah regresi yang bebas dari autokorelasi. Uji Durbin Watson hanya digunakan untuk autokorelasi tngkat satu dan mensyaratkan adanya intercept (konstanta) dalam model regresi dan tidak ada variable lag antra variable independen. Metode pengujian yang sering digunakan adalah dengan uji Durbin-Watson dengan ketentuan sebagai berikut:

1. Jika $d$ lebih kecil dari $d L$ atau lebih besar dari $(4-d L)$ maka hipotesis nol ditolak, yang berarti terdapat autokorelasi.

2. Jika $d$ terletak antara $d U$ dan $(4-d U)$, maka hipotesis nol diterima, yang berarti tidak ada autokorelasi. 
3. Jika $d$ terletak antara $d L$ dan $d U$ atau diantara $(4-d U)$ dan $(4-d L)$ maka tidak menghasilkan kesimpulan yang pasti.

Pada tahap ini penulis menggunakan program SPSS untuk mengetahui hasil Uji Durbin-Watson dan hasilnya sebagai berikut:

Tabel 2. Uji Durbin-Watson

\begin{tabular}{|c|c|c|c|c|c|}
\hline Model & $\mathrm{R}$ & R Square & Adjusted R Square & $\begin{array}{l}\text { Std. Error of the } \\
\text { Estimate }\end{array}$ & Durbin-Watson \\
\hline 1 & $.989^{\mathrm{a}}$ & .979 & .968 & 976069.272 & 2.336 \\
\hline \multicolumn{6}{|c|}{ a. Predictors: (Constant), Jumlah_Tenaga_Kerja, Jumlah_Industri_Kecil } \\
\hline \multicolumn{6}{|c|}{ b. Dependent Variable: Nilai_Produksi } \\
\hline
\end{tabular}

Berdasarkan hasil uji Durbin-Watson pada Tabel 2 diketahui nilai $D W=2,336$, selanjutnya nilai ini akan kita bandingkan dengan nilai tabel signifikasi $5 \%$ pada tabel 3.1, jumlah sampel $N=7$ dan jumlah variable independen $(K)=2$. Maka diperoleh nilai $d U=1,896$. Nilai $D W=2,336$ lebih besar dari batas atas $(d U)$ yakni 1,896 dan kurang dari $(4-d U)=(4-1,896)=2,104$ sehingga dapat disimpulkan bahwa tidak terdapat autokorelasi.

\section{Kesimpulan}

Berdasarkan hasil analisis diketahui tidak terdapat autokorelasi antara jumlah industri dan tenaga kerja terhadap nilai produksi pada industri kecil di Kabupaten Lamongan. Dalam pengambilan sampel data untuk diuji autokorelasi menggunakan uji Durbin Watson minimal berjumlah 6 data untuk jumlah variable independen $(\mathrm{k})=1$, minimal berjumlah 7 data untuk jumlah variable independen $(\mathrm{k})=2$, dan seterusnya.

\section{Daftar Pustaka}

[1] S. M. Keuangan, "No. 316/KMK. 016/1994," SK tersebut mewajibkan Badan Usaha Milik Negara untuk menyisihkan, pp. 1-5, 1994.

[2] D. Kurniawan, "Regresi linier," R-Foundation Stat. Comput. Vienna, Austria, vol. 17, 2008. 